\title{
Association of changes in delayed gadolinium- enhanced MRI of cartilage (dGEMRIC) with changes in cartilage thickness in the medial tibiofemoral compartment of the knee: a 2 year follow-up study using 3.0 T MRI
}

\author{
Michel D Crema, ${ }^{1,2,3}$ David J Hunter, ${ }^{4}$ Deborah Burstein, ${ }^{5}$ Frank W Roemer, ${ }^{1,6}$ \\ Ling Li, ${ }^{7}$ Felix Eckstein, ${ }^{8,9}$ Nitya Krishnan, ${ }^{5}$ Marie-Pierre Hellio Le-Graverand, ${ }^{10}$ \\ Ali Guermazi ${ }^{1,2}$
}

Handling editor Tore K Kvien

For numbered affiliations see end of article.

\section{Correspondence to} Dr Michel D Crema, Department of Radiology, Quantitative Imaging Center, Boston University School of Medicine, 820 Harrison Avenue, FGH Building, 3rd Floor, Boston, MA 02118, USA; michelcrema@gmail.com

Received 7 December 2012 Revised 14 May 2013 Accepted 29 June 2013 Published Online First 19 July 2013
CrossMark

To cite: Crema $\mathrm{MD}$ Hunter DJ, Burstein D, et al. Ann Rheum Dis 2014;73:1935-1941.

\section{ABSTRACT}

Objective To determine the association between changes in the delayed gadolinium-enhanced MRI of cartilage (dGEMRIC) index over 2 years as a measure of cartilage proteoglycan concentration, with changes in cartilage thickness in the medial tibiofemoral compartment of knees in middle-aged women.

Methods One hundred and forty-eight women (one knee for each subject) aged $\geq 40$ years were included. 3.0 T MR images of the knee were acquired at baseline, 1 year and 2 years. Three-dimensional (3D) spoiled gradient recalled echo (SPGR) sequences (for cartilage thickness) and 3D inversion recovery-prepared SPGR sequences after dGEMRIC were acquired. Segmentation was performed in the medial central (weight-bearing) femur and tibia to determine cartilage proteoglycan concentration and thickness. The association of change in the dGEMRIC indices between baseline and 1-year follow-up with (a) concomitant changes in cartilage thickness and (b) change in cartilage thickness between 1 and 2 years was assessed using linear regression.

Results In the whole-sample model, a decrease in dGEMRIC indices over time at the central medial femur significantly predicted an increase in cartilage thickness at both the central medial femur $(p=0.008)$ and the medial tibia ( $p=0.04)$.

Conclusions A decrease in dGEMRIC indices was associated with an increase in cartilage thickness in the medial compartment. Our results suggest that an increase in cartilage thickness may also be related to a decrease in proteoglycan concentration, which may represent swelling of cartilage in early stages of degeneration.

\section{INTRODUCTION}

Delayed gadolinium-enhanced MRI of cartilage (dGEMRIC) can assess the composition of the cartilage matrix before morphological surface changes appear. ${ }^{1-3}$ It was specifically created to assess the glycosaminoglycan (GAG) concentration of the cartilage matrix. ${ }^{45}$ Ions within the interstitial fluid of cartilage are distributed in relation to the concentration of negatively charged GAG molecules (proteoglycan content). Gadolinium diethylenetriaminepentaacetic acid $\left(\right.$ Gd-DTPA $\left.{ }^{2-}\right)$, the contrast agent used in dGEMRIC, distributes in areas within the cartilage where the negatively charged GAG content is low. Since the concentration of Gd-DTPA ${ }^{2-}$ can be approximated by measuring T1, T1 assessment of cartilage after intravenous administration of Gd-DTPA ${ }^{2-}$ allows evaluation of the GAG concentration of cartilage. ${ }^{6}$ The dGEMRIC measurements have been validated in clinical studies, corresponding to reference standard measurements for GAG histology and biochemistry. ${ }^{5}$ dGEMRIC has been shown to demonstrate variations in morphologically intact cartilage and may have a bearing on the development of knee osteoarthritis (OA). ${ }^{7}$ Previous experimental studies demonstrated the usefulness of dGEMRIC measurements in the detection of alterations in the GAG content of cartilage matrix, when using histological data as the reference. ${ }^{89}$

Compositional MRI techniques have the potential to become markers of the incidence and progression of OA, especially in the earliest stages of disease and could be useful in clinical trials when testing disease-modifying OA drugs. ${ }^{10}{ }^{11}$ Before dGEMRIC can be validated as a marker, an association must be shown between worsening of the dGEMRIC index and morphological changes over time. One previous study showed that a low dGEMRIC index at baseline was not associated with longitudinal cartilage thinning, after correction for multiple testing. ${ }^{12}$

MRI accurately measures cartilage loss longitudinally via quantitative assessment. ${ }^{13-16}$ Algorithms have been developed for measuring cartilage thickness in defined subregions of the femorotibial joint, ${ }^{17}{ }^{18}$ and subregional changes in the central and external medial tibia and in the central part of the weight-bearing femoral condyle have been shown to exceed changes in other subregions of the medial femorotibial compartment. ${ }^{19} 20$

The aim of this study was to assess the association of changes in dGEMRIC indices with changes in cartilage thickness in the medial tibiofemoral compartment of knees in a sample of middle-aged women, over a 2 -year period, using 3.0 T MRI. 


\section{MATERIAL AND METHODS Subjects}

A total of 180 women aged $\geq 40$ years participated in the study. The recruitment has been described in detail previously. ${ }^{12} 1320$ Briefly, subjects were recruited at seven clinical centres to participate in a longitudinal 2-year observational study to evaluate progression of knee OA. Conventional weight-bearing anteroposterior knee radiographs were obtained at each centre to establish the baseline status of knee OA using the Kellgren and Lawrence (KL) grading scale. ${ }^{21}$

Inclusion criteria for $\mathrm{OA}$ participants were frequent symptoms, mild to moderate radiographic OA in the medial compartment (KL 2 or 3), a body mass index (BMI) of $\geq 30$ and a medial tibiofemoral joint space width $\geq 2 \mathrm{~mm}$ in a posteroanterior modified Lyon-Schuss radiographic view. ${ }^{22}$ Inclusion criteria for the control group were complete absence of bilateral knee symptoms, KL grade $\leq 1$ in either knee and a BMI $\leq 28$. Furthermore, knee alignment was determined by the anatomic-axis angle measured on the baseline posteroanterior Lyon-Schuss radiographs, using the method described by Kraus et al. $^{23}$ The study was conducted in compliance with local institutional review boards, informed consent regulations, the International Conference on Harmonisation Good Clinical Practice Guidelines and the Declaration of Helsinki.

All subjects with missing data on cartilage thickness in the medial tibiofemoral compartment, on medial tibiofemoral dGEMRIC, on demographic and KL grade data or on knee alignment data were excluded from the analysis (figure 1).

\section{MR imaging protocol}

Siemens Magnetom Trio 3.0 Tesla (T) magnets (Siemens AG, Erlangen, Germany) were used at three of the seven study sites, two sites used Signa Excite/Genesis 3.0 T MRI long-bore magnets and two used General Electric short-bore magnets (GE Healthcare Technologies, Waukesha, Wisconsin, USA).

For assessment of cartilage thickness, double oblique coronal spoiled gradient recalled acquisition at steady state (SPGR) sequences with selective water excitation were acquired at baseline, 1 year and 2 years with an in-plane resolution of $0.31 \mathrm{~mm} \times 0.31 \mathrm{~mm}$ and a slice thickness of $1.0 \mathrm{~mm} \quad(\mathrm{TE}=7.2-$ $8.5 \mathrm{~ms}, \mathrm{TR}=16-17 \mathrm{~ms}$, flip angle $=12^{\circ}$, bandwidth $=31.25 \mathrm{kHz}$ $(\mathrm{GE})$ or $130 \mathrm{~Hz} /$ pixel (Siemens), matrix size $=512 \times 512$ ).

For dGEMRIC assessment, subjects were intravenously injected with $0.2 \mathrm{mmol} / \mathrm{kg}$ of Gd-DTPA ${ }^{2-}$ and asked to walk or use a pedal exerciser for $10 \mathrm{~min}$ to aid the transport of the contrast agent into cartilage. Sagittal 3D inversion recoveryprepared SPGR sequences with selective water excitation were obtained $90 \mathrm{~min}$ after Gd-DTPA ${ }^{2-}$ administration, for baseline and 1-year imaging, with similar parameters as described above.

A sagittal fat-suppressed 2D dual-echo fast spin echo sequence was also acquired at baseline and at 1 year with an in-plane resolution of $0.63 \mathrm{~mm} \times 0.63 \mathrm{~mm}$ and a slice thickness of $3.0 \mathrm{~mm} \quad\left(\mathrm{TE}=9 / 39 \mathrm{~ms}, \quad \mathrm{TR}=2700-3600, \quad\right.$ flip angle $=170^{\circ}$, bandwidth $=32 \mathrm{kHz}$ (GE) or $199 \mathrm{~Hz} /$ pixel, (Siemens), matrix size $=256 \times 256$ ).

\section{Cartilage thickness measurement}

Seven technicians with formal training and thorough experience in cartilage segmentation performed the segmentation of the medial femorotibial cartilage on all the coronal images. ${ }^{12} 1320$ Images were read in pairs, with blinding to the time point of acquisition. Manual tracing of the total subchondral bone area and the cartilaginous joint surface area of the medial tibia and the central (weight-bearing) medial femoral condyle was performed. Femoral cartilage was analysed in a region of interest between the intercondylar notch and $60 \%$ of the distance to the posterior end of the femoral condyles in the coronal view. ${ }^{20}$ All segmented slices of each dataset were reviewed by a single person (FE) who performed quality control of all segmentations. $^{24} 25$ Morphological cartilage changes were computed using the difference of the mean cartilage thickness over the total area of subchondral bone between baseline and 1 year, as well as between the 1-year and 2-year follow-up, at either the medial tibia or central medial femoral condyle. Test-retest measurements of the mean cartilage thickness over the total area of subchondral bone using total plates to ensure reproducibility have been previously described in detail. ${ }^{13}$

\section{dGEMRIC assessment}

dGEMRIC was assessed at baseline and at 1 year. For each dataset, one medial tibiofemoral sagittal section that included both articular cartilage and medial meniscus was chosen for analysis (matched for baseline and follow-up images). This section was located in the middle of the medial tibiofemoral compartment using coronal images as a guide. Areas of articular cartilage were hand-segmented using sagittal dual-echo T2-weighted images as a guide. T1 $(\mathrm{Gd})$ maps were then generated using custom-coded software (MRI Mapper; Beth Israel Deaconess
Figure 1 Flow chart of the study cohort. Data were missing owing to self-withdrawal, failure to comply with follow-up, protocol violation or artefacts during MRI acquisition. In total, 32 subjects were excluded. FU, follow-up; KL, Kellgren and Lawrence.

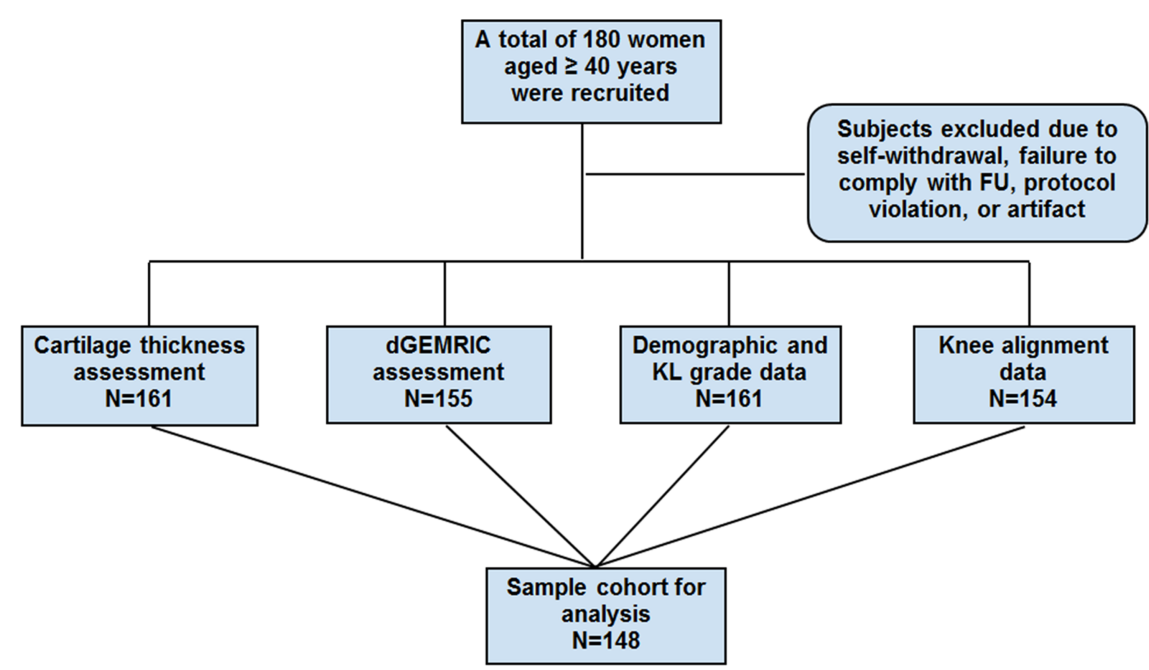


Medical Center) in MatLab 7 that uses a pixel-by-pixel threeparameter T1 fit. $^{26}$ The reported T1(Gd) value (dGEMRIC index) is the average of the $\mathrm{T} 1(\mathrm{Gd})$ values in a given region of interest. Areas of cartilage with a lower dGEMRIC index are assumed to have low concentration of GAG. ${ }^{27}$

Three regions were segmented in the articular cartilage of each section: the first contained the central medial femoral cartilage, which was defined as cartilage between the outer edges of the anterior and posterior horns of the meniscus; the second contained all of the medial tibial plateau cartilage; and the third contained the posterior medial femoral cartilage, posteriorly to the outer edge of the posterior horn of the meniscus. The posterior region was not considered in our analysis since it was not segmented for cartilage thickness assessment.

We considered different groups according to changes in the dGEMRIC indices over time in the same medial region (figure 2): (a) the increased group (dGEMRIC index higher at 1 year than at baseline); (b) the decreased group (dGEMRIC index lower at 1 year than at baseline); and (c) the stable group (dGEMRIC index stable at 1 year compared with baseline). Regions with stable dGEMRIC indices were not considered in the analysis.

\section{Statistical analyses}

First, we assessed the association of changes in the dGEMRIC indices with changes in cartilage thickness in groups of knees defined by KL grade: (a) KL grades 0 and 1; (b) KL grade 2; (c) KL grade 3. Owing to this stratification, we had insufficient power to test the effects of the increased and decreased dGEMRIC groups separately. For each region, we determined the associations of changes in dGEMRIC indices at 1 year with changes in cartilage thickness at 1 year. We also determined the association between changes in dGEMRIC indices at 1 year with changes in cartilage thickness during the second year. Associations were obtained using linear regression models, with adjustments for age, BMI and knee malalignment. The $\beta 1$ coefficients from the linear regression models represent the level of change in cartilage thickness over time (Y; outcome) measured for one unit 'decrease' (worsening in GAG concentration) in dGEMRIC values (predictor), as expressed by, $Y=\beta 0+\beta 1 X$ (where $\mathrm{X}$ represents the amount of change in dGEMRIC at 1 year from baseline). A positive $\beta 1$ value represents a decrease in both cartilage thickness and dGEMRIC; a negative $\beta 1$ value represents an increase in cartilage thickness but a decrease in dGEMRIC.

Second, we used all the knees in the study to assess the same associations as described above in which we considered the increased and decreased dGEMRIC groups separately. We adjusted the results for age, BMI, knee malalignment and for the KL grade. In each group considered in the second analysis, a positive $\beta 1$ value represents a change in cartilage thickness in the same direction of change as the dGEMRIC index; a negative $\beta 1$ value represents a change in cartilage thickness in the opposite direction to the change in the dGEMRIC index.

We also investigated whether there was any association of changes in the dGEMRIC index at the central medial femur

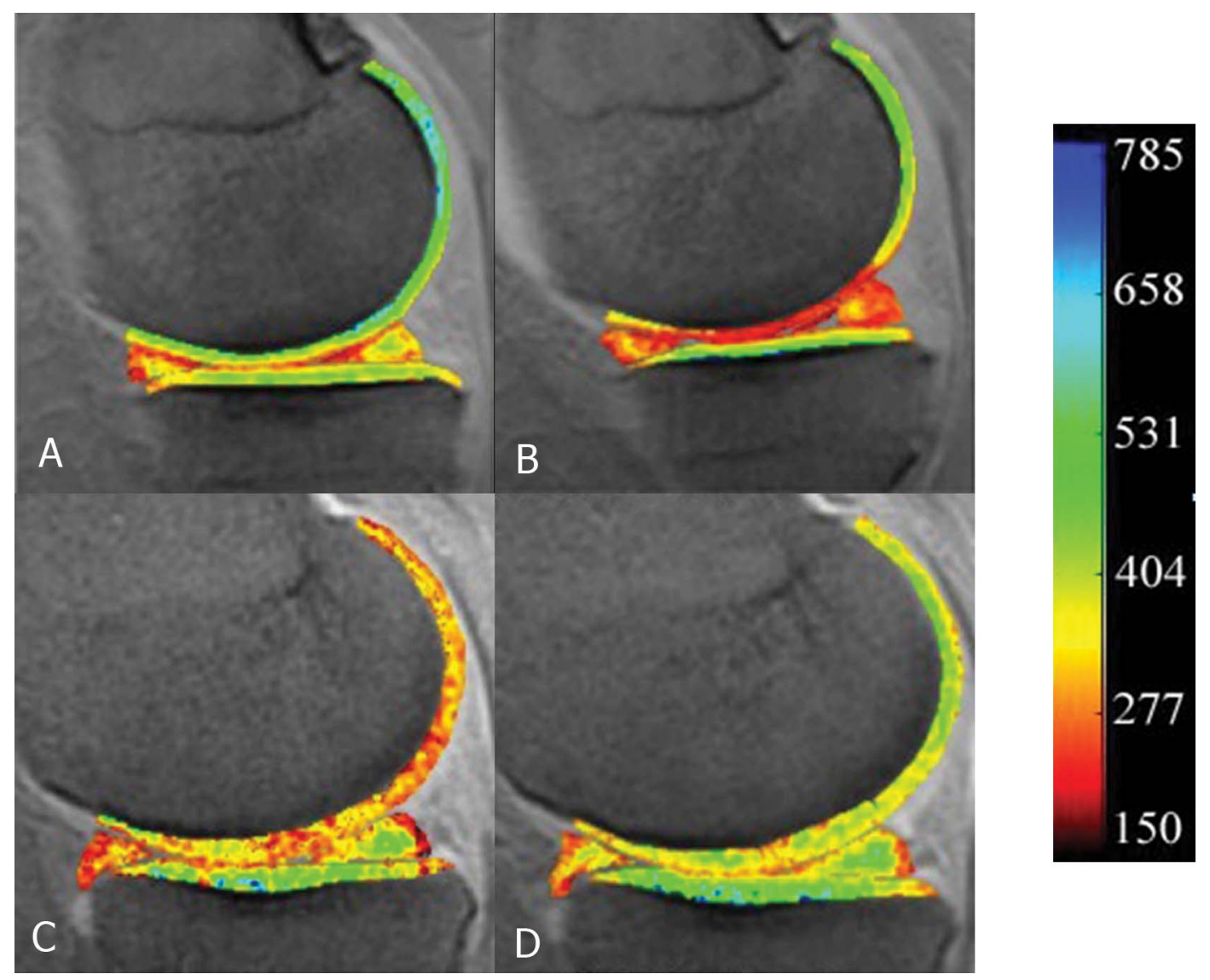

Figure 2 Changes in delayed gadolinium-enhanced MRI of cartilage (dGEMRIC) at the central medial femur over 1 year: (A) baseline and (B) the decrease at 1 year in the same medial compartment. Changes in dGEMRIC at the central and posterior medial femur: (C) baseline and (D) the increase at 1 year in the same medial compartment. Corresponding colour map; value in milliseconds. 
with changes in cartilage thickness at the medial tibia and vice versa. All statistical analyses were performed using SAS software (SAS Institute Inc, Cary, North Carolina, USA, release V.9.1).

\section{RESULTS}

\section{Participants' characteristics and mean dGEMRIC indices}

The study sample comprised 148 women (one knee for each subject; 296 medial regions), with a mean age of 56.8 years ( \pm 8.7 ) and mean BMI of $29.3 \mathrm{~kg} / \mathrm{m}^{2}( \pm 7.5)$. Of these, the control group contained $92(62.2 \%)$ subjects, with a mean age of 56.3 $( \pm 9)$ years and a mean BMI of $24.8( \pm 4.4)$. In the control group, 88 knees had baseline KL grade 0 and four had baseline KL grade 1 . The OA group had 56 subjects (37.8\%), with a mean age of $57.4( \pm 8.2)$ years and a mean BMI of $36.7( \pm 5.4)$. In the OA group, 30 knees had baseline KL grade 2 and 26 had baseline KL grade 3 . The only significant difference between the OA group and the control group was in the mean BMI $(\mathrm{p}<0.05)$.

At the central medial femur, the mean of the dGEMRIC indices at baseline was $581.1 \mathrm{~ms}$ (SD $122.2 \mathrm{~ms}$; range 263$978 \mathrm{~ms}$ ) and at 1 year was $599.1 \mathrm{~ms}$ (SD $126.2 \mathrm{~ms}$; range 318$905 \mathrm{~ms}$ ). At the medial tibia, the mean dGEMRIC index at baseline was $563.1 \mathrm{~ms}$ (SD $102.3 \mathrm{~ms}$; range $300-818 \mathrm{~ms}$ ) and at 1 year was $611.6 \mathrm{~ms}$ (SD $107.3 \mathrm{~ms}$; range 351-1032 ms).

\section{Association of changes in dGEMRIC indices with changes in cartilage thickness stratified by the $\mathrm{KL}$ grade}

In knees with baseline KL grades 0 and 1 (table 1), there were no significant associations, after adjustments, between changes in dGEMRIC indices and changes in cartilage thickness when changes in the same region were considered. However, a decrease in dGEMRIC indices at the central medial femur from baseline to 1 year follow-up was significantly associated with an increase in cartilage thickness at the medial tibia from the 1- to 2-year follow-up, after adjustments $(p=0.02)$.
In knees with baseline KL grade 2 (table 1), there was a significant association at the central medial femur between the decrease in dGEMRIC indices and the increase in cartilage thickness in the first year, after adjustments $(p=0.04)$.

In knees with baseline KL grade 3, there were no significant associations between changes in dGEMRIC indices and changes in cartilage thickness (data not shown).

\section{Association of changes in dGEMRIC indices with changes in cartilage thickness in the whole sample stratified by dGEMRIC groups: increase and decrease}

Of 296 subregions assessed, in the first year $185(62.5 \%)$ showed an increase in dGEMRIC indices, 107 (36.1\%) showed a decrease in dGEMRIC indices and in four (1.4\%) the dGEMRIC indices remained the same. We found that a decrease in dGEMRIC indices at the central medial femur in the first year was significantly associated with an increase in cartilage thickness in the second year at both the central medial femur $(p=0.01)$ and at the medial tibia $(p=0.04)$, after adjustments (table 2). No significant associations were found for the increased dGEMRIC group.

\section{DISCUSSION}

We demonstrated that a decrease in the dGEMRIC index was associated with an increase in cartilage thickness in certain regions of the medial compartment of the knee. To the best of our knowledge, this is the first study to assess the associations of changes in dGEMRIC indices with changes in cartilage thickness.

Previous studies attempted to show that alterations in cartilage using compositional MRI are associated with morphological changes in cartilage. In a study which used data from the OA Initiative, Joseph et $a^{28}$ evaluated the relationship between baseline T2 values of cartilage and morphological changes of cartilage in the patella over 3 years and showed that knees with increased cartilage lesion scores had significantly greater baseline

Table 1 Associations of changes in dGEMRIC indices with changes in cartilage thickness over time, stratified by the Kellgren and Lawrence (KL) grade

\begin{tabular}{|c|c|c|c|c|c|c|}
\hline \multicolumn{2}{|c|}{ Outcome: changes in cartilage thickness } & \multirow{2}{*}{$\begin{array}{l}\text { Predictor: decrease in dGEMRIC } \\
\text { from baseline to } 1 \text { year }\end{array}$} & \multicolumn{2}{|l|}{ Unadjusted } & \multicolumn{2}{|l|}{ Adjusted* } \\
\hline Timeline & Region & & 及1(SE) & p Value & B1(SE) & p Value \\
\hline \multicolumn{7}{|l|}{$\mathrm{KL}$ grades 0 and 1} \\
\hline 1 Year-baseline & $\begin{array}{l}\text { Medial tibia } \\
\text { Medial tibia }\end{array}$ & $\begin{array}{l}\text { Medial tibia } \\
\text { Central medial femur }\end{array}$ & $\begin{array}{r}-0.000025(0.000040) \\
0.000066(0.000044)\end{array}$ & $\begin{array}{l}0.54 \\
0.14\end{array}$ & $\begin{array}{r}-0.000020(0.000045) \\
0.000061(0.000047)\end{array}$ & $\begin{array}{l}0.65 \\
0.20\end{array}$ \\
\hline 2 Years-1 year & $\begin{array}{l}\text { Medial tibia } \\
\text { Medial tibia }\end{array}$ & $\begin{array}{l}\text { Medial tibia } \\
\text { Central medial femur }\end{array}$ & $\begin{array}{l}-0.000062(0.000057) \\
-0.000150(0.000061)\end{array}$ & $\begin{array}{l}0.28 \\
0.02 \dagger\end{array}$ & $\begin{array}{l}-0.000044(0.000071) \\
-0.000176(0.000072)\end{array}$ & $\begin{array}{l}0.54 \\
0.02 \dagger\end{array}$ \\
\hline 1 Year-baseline & $\begin{array}{l}\text { Central medial femur } \\
\text { Central medial femur }\end{array}$ & $\begin{array}{l}\text { Medial tibia } \\
\text { Central medial femur }\end{array}$ & $\begin{array}{l}0.000072(0.000071) \\
0.000122(0.000078)\end{array}$ & $\begin{array}{l}0.31 \\
0.12\end{array}$ & $\begin{array}{l}0.000097(0.000078) \\
0.000033(0.000084)\end{array}$ & $\begin{array}{l}0.22 \\
0.70\end{array}$ \\
\hline 2 Years-1 year & $\begin{array}{l}\text { Central medial femur } \\
\text { Central medial femur }\end{array}$ & $\begin{array}{l}\text { Medial tibia } \\
\text { Central medial femur }\end{array}$ & $\begin{array}{l}-0.000082(0.000079) \\
-0.000014(0.000088)\end{array}$ & $\begin{array}{l}0.30 \\
0.87\end{array}$ & $\begin{array}{r}-0.000014(0.000097) \\
0.000025(0.000104)\end{array}$ & $\begin{array}{l}0.88 \\
0.81\end{array}$ \\
\hline \multicolumn{7}{|l|}{ KL grade 2} \\
\hline 1 Year-baseline & $\begin{array}{l}\text { Medial tibia } \\
\text { Medial tibia }\end{array}$ & $\begin{array}{l}\text { Medial tibia } \\
\text { Central medial femur }\end{array}$ & $\begin{array}{l}0.000125(0.000113) \\
0.000010(0.000103)\end{array}$ & $\begin{array}{l}0.28 \\
0.92\end{array}$ & $\begin{array}{l}0.000137(0.000120) \\
0.000041(0.000111)\end{array}$ & $\begin{array}{l}0.26 \\
0.71\end{array}$ \\
\hline 2 Years-1 year & $\begin{array}{l}\text { Medial tibia } \\
\text { Medial tibia }\end{array}$ & $\begin{array}{l}\text { Medial tibia } \\
\text { Central medial femur }\end{array}$ & $\begin{array}{r}-0.000170(0.000155) \\
0.000033(0.000141)\end{array}$ & $\begin{array}{l}0.28 \\
0.82\end{array}$ & $\begin{array}{r}-0.000258(0.000148) \\
0.000125(0.000139)\end{array}$ & $\begin{array}{l}0.09 \\
0.38\end{array}$ \\
\hline 1 Year-baseline & $\begin{array}{l}\text { Central medial femur } \\
\text { Central medial femur }\end{array}$ & $\begin{array}{l}\text { Medial tibia } \\
\text { Central medial femur }\end{array}$ & $\begin{array}{r}0.000067(0.000164) \\
-0.000387(0.000164)\end{array}$ & $\begin{array}{l}0.69 \\
0.03+\end{array}$ & $\begin{array}{r}0.000113(0.000178) \\
-0.000378(0.000176)\end{array}$ & $\begin{array}{l}0.53 \\
0.04 \dagger\end{array}$ \\
\hline 2 Years-1 year & $\begin{array}{l}\text { Central medial femur } \\
\text { Central medial femur }\end{array}$ & $\begin{array}{l}\text { Medial tibia } \\
\text { Central medial femur }\end{array}$ & $\begin{array}{r}-0.000175(0.000253) \\
0.000213(0.000222)\end{array}$ & $\begin{array}{l}0.49 \\
0.35\end{array}$ & $\begin{array}{r}-0.000378(0.000214) \\
0.000344(0.000192)\end{array}$ & $\begin{array}{l}0.09 \\
0.09\end{array}$ \\
\hline
\end{tabular}


Table 2 Associations of changes in dGEMRIC indices with changes in cartilage thickness over time, stratified by changes in dGEMRIC: increased and decreased dGEMRIC groups

\begin{tabular}{|c|c|c|c|c|c|c|}
\hline \multicolumn{2}{|c|}{ Outcome: changes in cartilage thickness } & \multirow{2}{*}{$\begin{array}{l}\text { Predictor: decrease in dGEMRIC } \\
\text { from baseline to } 1 \text { year }\end{array}$} & \multicolumn{2}{|l|}{ Unadjusted } & \multicolumn{2}{|l|}{ Adjusted* } \\
\hline Timeline & Region & & $\beta 1$ (SE) & p Value & $\beta 1$ (SE) & p Value \\
\hline \multicolumn{7}{|c|}{ Decreased dGMERIC group $\ddagger$} \\
\hline 1 Year-baseline & $\begin{array}{l}\text { Medial tibia } \\
\text { Medial tibia }\end{array}$ & $\begin{array}{l}\text { Medial tibia } \\
\text { Central medial femur }\end{array}$ & $\begin{array}{l}0.000058(0.000117) \\
0.000170(0.000091)\end{array}$ & $\begin{array}{l}0.62 \\
0.07\end{array}$ & $\begin{array}{l}0.000180(0.000158) \\
0.000119(0.000097)\end{array}$ & $\begin{array}{l}0.26 \\
0.23\end{array}$ \\
\hline 2 Years-1 year & $\begin{array}{l}\text { Medial tibia } \\
\text { Medial tibia }\end{array}$ & $\begin{array}{l}\text { Medial tibia } \\
\text { Central medial femur }\end{array}$ & $\begin{array}{l}-0.000164(0.000172) \\
-0.000307(0.000131)\end{array}$ & $\begin{array}{l}0.35 \\
0.02 \dagger\end{array}$ & $\begin{array}{l}-0.000093(0.000211) \\
-0.000304(0.000146)\end{array}$ & $\begin{array}{l}0.66 \\
0.04 \dagger\end{array}$ \\
\hline 1 Year-baseline & $\begin{array}{l}\text { Central medial femur } \\
\text { Central medial femur }\end{array}$ & $\begin{array}{l}\text { Medial tibia } \\
\text { Central medial femur }\end{array}$ & $\begin{array}{l}0.000032(0.00021) \\
0.000384(0.000173)\end{array}$ & $\begin{array}{l}0.88 \\
0.03+\end{array}$ & $\begin{array}{l}0.000186(0.000212) \\
0.000287(0.000167)\end{array}$ & $\begin{array}{l}0.39 \\
0.09\end{array}$ \\
\hline 2 Years-1 year & $\begin{array}{l}\text { Central medial femur } \\
\text { Central medial femur }\end{array}$ & $\begin{array}{l}\text { Medial tibia } \\
\text { Central medial femur }\end{array}$ & $\begin{array}{l}-0.000192(0.000248) \\
-0.000446(0.000178)\end{array}$ & $\begin{array}{l}0.44 \\
0.02 \dagger\end{array}$ & $\begin{array}{l}-0.000141(0.000304) \\
-0.000486(0.000174)\end{array}$ & $\begin{array}{l}0.65 \\
0.01 \dagger\end{array}$ \\
\hline \multicolumn{7}{|c|}{ Increased dGEMRIC group $\ddagger$} \\
\hline 1 Year-baseline & $\begin{array}{l}\text { Medial tibia } \\
\text { Medial tibia }\end{array}$ & $\begin{array}{l}\text { Medial tibia } \\
\text { Central medial femur }\end{array}$ & $\begin{array}{r}0.000019(0.000073) \\
-0.000039(0.000088)\end{array}$ & $\begin{array}{l}0.80 \\
0.66\end{array}$ & $\begin{array}{c}0.000019(0.000079) \\
-0.000042(0.00098)\end{array}$ & $\begin{array}{l}0.81 \\
0.67\end{array}$ \\
\hline 2 Years-1 year & $\begin{array}{l}\text { Medial tibia } \\
\text { Medial tibia }\end{array}$ & $\begin{array}{l}\text { Medial tibia } \\
\text { Central medial femur }\end{array}$ & $\begin{array}{l}0.000053(0.000105) \\
0.000147(0.000130)\end{array}$ & $\begin{array}{l}0.61 \\
0.26\end{array}$ & $\begin{array}{l}0.000088(0.000123) \\
0.000113(0.000155)\end{array}$ & $\begin{array}{l}0.48 \\
0.47\end{array}$ \\
\hline 1 Year-baseline & $\begin{array}{l}\text { Central medial femur } \\
\text { Central medial femur }\end{array}$ & $\begin{array}{l}\text { Medial tibia } \\
\text { Central medial femur }\end{array}$ & $\begin{array}{l}0.000149(0.000122) \\
0.000027(0.000145)\end{array}$ & $\begin{array}{l}0.22 \\
0.85\end{array}$ & $\begin{array}{r}0.000132(0.000130) \\
-0.000090(0.000142)\end{array}$ & $\begin{array}{l}0.31 \\
0.53\end{array}$ \\
\hline 2 Year-1 year & $\begin{array}{l}\text { Central medial femur } \\
\text { Central medial femur }\end{array}$ & $\begin{array}{l}\text { Medial tibia } \\
\text { Central medial femur }\end{array}$ & $\begin{array}{r}-0.000178(0.000155) \\
0.000274(0.000196)\end{array}$ & $\begin{array}{l}0.25 \\
0.17\end{array}$ & $\begin{array}{r}-0.000062(0.000161) \\
0.000237(0.000212)\end{array}$ & $\begin{array}{l}0.70 \\
0.27\end{array}$ \\
\hline
\end{tabular}

mean T2 values than knees with no changes in cartilage morphology scores. However, Eckstein et al ${ }^{12}$ found no significant association between baseline cartilage matrix alterations on both T2 and dGEMRIC and cartilage thickness loss over 2 years, after correction for multiple testing.

Our study considered the association of changes over time in the cartilage matrix of specific regions in the medial tibiofemoral compartment as assessed by dGEMRIC, with changes in quantitatively assessed cartilage thickness in the same regions. One would assume that a decrease in dGEMRIC indices in a given region, corresponding to a decrease in the GAG concentration of the cartilage matrix, would be associated with morphological chondral changes, more likely with cartilage loss in the same region. Surprisingly, we found that a decrease in dGEMRIC indices was significantly associated with an increase in cartilage thickness.

Our results should be interpreted carefully: the relationship was only shown in knees without OA (KL grades 0 and 1) and in knees with early radiographic OA (KL grade 2) in our first analysis, with a relatively short follow-up. We may hypothesise that the decrease in dGEMRIC indices seen over the first year represents very early degeneration of the cartilage matrix, possibly associated with swelling and softening of the articular cartilage $^{29}{ }^{30}$ that occurs before cartilage loss is detected and which would increase cartilage thickness on MRI. It is also likely that such an association, demonstrated again in our second analysis of the whole sample, can be linked to knees without radiographic OA or with early radiographic OA $(82.4 \%$ of the whole sample; $N=122$ ). Supporting our hypothesis, previous studies have demonstrated that cartilage may be thicker in specific subregions of tibiofemoral compartments in knees with preradiographic OA and in early stages of OA. ${ }^{31-33}$ Furthermore, a study conducted by Chen et $a l^{34}$ showed that histological features of early cartilage degeneration including corruption of cartilage matrix fibrillar architecture correlated with the swelling potential of cartilage.
Our study demonstrated that thickening of cartilage over time was associated with a decrease in cartilage GAG concentration as measured by dGEMRIC in some regions of the medial compartments of pre-radiographic and early radiographic OA knees. This association also supports the suggestion that cartilage thickening may occur in early stages of the disease. Although dGEMRIC demonstrates potential to detect early degenerative alterations in the cartilage matrix, the technique is difficult to implement in routine clinical practice because it is invasive (need for intravenous contrast administration) and time consuming.

Some limitations to our study need mentioning. First, it is not known how low the dGEMRIC index needs to be in a given region of the knee at baseline for future cartilage loss to occur. It is possible that a decrease in the dGEMRIC index from a relatively high baseline index might not be sufficient to predict cartilage loss. Second, we considered any decrease or increase in absolute dGEMRIC indices as 'change' in dGEMRIC and very small changes may not be sufficient to predict cartilage loss. Third, our data cover a relatively short time of only 2 years. The associations we found might change if the intervals between assessments of dGEMRIC and cartilage thickness were longer. Fourth, we had no arthroscopic or surgical data to confirm that softening and swelling of cartilage occurred. Fifth, our sample comprised only middle-aged women and our results might not apply to men or young, athletic subjects. Finally, we assessed medial tibiofemoral cartilage morphology quantitatively, which is very sensitive to changes in thickness and volume, ${ }^{13}$ but is less sensitive to small focal cartilage defects. We might have missed some incidence or progression of small focal cartilage defects, especially in the knees with KL grades $0-2.3536$

In conclusion, we showed that a decrease in dGEMRIC indices was associated with an increase in cartilage thickness in the medial tibiofemoral compartment, mainly in knees without radiographic OA or with early radiographic OA, over a 2-year period. The association might be related to swelling and softening of the medial tibiofemoral cartilage, where a decrease in the 
GAG concentration can be found in very early stages of cartilage degeneration. Such knowledge is of utmost importance for monitoring cartilage thickness in clinical trials. Ideally, morphological and compositional techniques should be combined to monitor cartilage status over time.

\section{Author affiliations}

${ }^{1}$ Department of Radiology, Quantitative Imaging Center, Boston University School of Medicine, Boston, Massachusetts, USA

${ }^{2}$ Boston Imaging Core Lab, Boston, Massachusetts, USA

${ }^{3}$ Department of Radiology, Hospital do Coração (HCor) and Teleimagem, São Paulo, Brazil

${ }^{4}$ Department of Rheumatology, Northern Clinical School, University of Sydney, Sydney, Australia

${ }^{5}$ Clinical Department of Radiology, Beth Israel Deaconess Medical Center, Harvard Medical School, Boston, Massachusetts, USA

${ }^{6}$ Department of Radiology, University of Erlangen, Erlangen, Germany

${ }^{7}$ Division of Research, New England Baptist Hospital, Boston, Massachusetts, USA

${ }^{8}$ Institute of Anatomy and Musculoskeletal Research, Paracelsus Medical University, Salzburg, Austria

${ }^{9}$ Chondrometrics $\mathrm{GmbH}$, Ainring, Germany

${ }^{10}$ Pfizer Global Research and Development, New London, Connecticut, USA

Acknowledgements We thank the participants and staff of the Pfizer A9001140 Osteoarthritis Study. We are grateful to the dedicated group of study coordinators whose skills were essential in assuring the successful conduct of this study: Manal Al-Suqi, Emily Brown, Janie Burchett, Sandra Chapman, Wandra Davis, Eugene Dunkle, Susan Federmann, Kristen Fredley, Donna Gilmore, Joyce Goggins, Sasha Goldberg, Norine Hall, Robert P Marquis, Thelma Munoz, Bruce Niles, Scott Squires and Kim Tally. We also thank the staff at Chondrometrics: Gudrun Goldmann, Linda Jakobi, Manuela Kunz, Dr Susanne Maschek, Sabine Mühlsimer, Annette Thebis and Barbara Wehr. We thank the dedicated MRI technologists, the Duke Image Analysis Laboratory staff: Maureen Ainslie, Cecil Charles, April Davis, Allison Fowlkes, Mark Ward and Scott White; the Pfizer A9001140 Team: Lydia Brunstetter, Peggy Coyle, Yevgenia Davidoff, Charles Packard, Ann Remmers, Mark Tengowski, Jeff Evelhoch (now Merck, Darmstadt, Germany) and John Kotyk (now Washington University, St Louis, Michigan, USA). Kenneth Brandt is also thanked for adjudicating on the radiographic readings. We also thank all the A9001140 site investigators: Julia Crim, Gary Hutchins, Chris Jackson, Virginia Byers Kraus, Nancy Lane, Thomas M Link, Sharmila Majumdar, Steve Mazzuca, Prasad Pottumarthi, Thomas Schnitzer, Mihra Taljanovic and Berchman Vaz. Finally, we thank all the staff of the participant institutions at which the MRIs were obtained: (1) University of Arizona (Department of Radiology), Tucson, Arizona, USA; (2) University of California at San Francisco (Department of Radiology), San Francisco, California, USA; (3) Beth Israel Deaconess Medical Center, Harvard Medical School (Department of Radiology), Boston, Massachusetts, USA; (4) Evanston Northwestern Healthcare (Department of Radiology), Evanston, Illinois, USA; (5) Duke Image Analysis Laboratory, Durham, Noeth Carolina, USA; (6) University of Utah (School of Medicine), Salt Lake City, Utah, USA; (7) Indiana University School of Medicine (Department of Radiology), Indianapolis, Indiana, USA.

Contributors Conception and design, drafting of the article, critical revision of the article for important intellectual content, final approval of the article: all authors. Analysis and interpretation of the data: MDC, DB, FE, LL and AG. Provision of study materials or patients: DJH and MPHLG. Statistical expertise: DJH and LL.

Funding This work was supported by Pfizer Inc.

Competing interests Michel D. Crema is shareholder and VP Musculoskeletal of Boston Imaging Core Lab (BICL), LLC. David J. Hunter receives grant support from Pfizer, Merck and DonJoy. Deborah Burstein receives grant support from Pfizer, Stryker, Gelita and Genzyme. Frank W. Roemer is shareholder and CMO of BICL, LLC. Felix Eckstein is CEO and co-owner of Chondrometrics GmbH. He provides consulting services to MerckSerono, Novartis and Sanofi Aventis. Marie-Pierre Hellio Le-Graverand is employed by Pfizer Inc. Ali Guermazi is President of BICL, LLC. He also provides consulting services for MerckSerono, Genzyme, Novartis, Stryker, and AstraZeneca.

Ethics approval The study was conducted in compliance with local institutional review boards, informed consent regulations, the International Conference on Harmonization Good Clinical Practices Guidelines, and the Declaration of Helsinki.

Provenance and peer review Not commissioned; externally peer reviewed.

\section{REFERENCES}

1 Burstein D, Gray M, Mosher T, et al. Measures of molecular composition and structure in osteoarthritis. Radiol Clin North Am 2009:47:675-86.
2 Crema MD, Roemer FW, Marra MD, et al. Articular cartilage in the knee: current MR imaging techniques and applications in clinical practice and research. Radiographics 2011;31:37-61.

3 Nieminen MT, Nissi MJ, Mattila L, et al. Evaluation of chondral repair using quantitative MRI. J Magn Reson Imaging 2012;36:1287-99.

4 Williams A, Gillis A, McKenzie C, et al. Glycosaminoglycan distribution in cartilage as determined by delayed gadolinium-enhanced MRI of cartilage (dGEMRIC): potential clinical applications. AJR Am J Roentgenol 2004;182:167-72.

5 Bashir A, Gray ML, Hartke J, et al. Nondestructive imaging of human cartilage glycosaminoglycan concentration by MRI. Magn Reson Med 1999;41:857-65.

6 Gillis A, Gray M, Burstein D. Relaxivity and diffusion of gadolinium agents in cartilage. Magn Reson Med 2002;48:1068-71.

7 Owman H, Tiderius CJ, Neuman P, et al. Association between findings on delayed gadolinium-enhanced magnetic resonance imaging of cartilage and future knee osteoarthritis. Arthritis Rheum 2008;58:1727-30.

8 Zilkens $C$, Miese F, Herten M, et al. Validity of gradient-echo three-dimensional delayed gadolinium-enhanced magnetic resonance imaging of hip joint cartilage: a histologically controlled study. Eur J Radiol 2013:82:e81-6.

9 Zilkens C, Miese FR, Crumbiegel C, et al. Magnetic resonance imaging and histology of ovine hip joint cartilage in two age populations: a sheep model with assumed healthy cartilage. Skeletal Radiol 2013;42:699-705.

10 Burstein D, Bashir A, Gray ML. MRI techniques in early stages of cartilage disease Invest Radiol 2000;35:622-38.

11 McAlindon TE, Nuite M, Krishnan N, et al. Change in knee osteoarthritis cartilage detected by delayed gadolinium enhanced magnetic resonance imaging following treatment with collagen hydrolysate: a pilot randomized controlled trial. Osteoarthritis Cartilage 2011;19:399-405.

12 Eckstein F, Le Graverand MP, Charles HC, et al. Clinical, radiographic, molecular and MRI-based predictors of cartilage loss in knee osteoarthritis. Ann Rheum Dis 2011:70:1223-30.

13 Eckstein F, Buck RJ, Burstein D, et al. Precision of 3.0 Tesla quantitative magnetic resonance imaging of cartilage morphology in a multicentre clinical trial. Ann Rheum Dis 2008;67:1683-8.

14 Peterfy CG, Guermazi A, Zaim S, et al. Whole-Organ Magnetic Resonance Imaging Score (WORMS) of the knee in osteoarthritis. Osteoarthritis Cartilage 2004;12:177-90.

15 Hunter DJ, Lo GH, Gale D, et al. The reliability of a new scoring system for knee osteoarthritis MRI and the validity of bone marrow lesion assessment: BLOKS (Boston Leeds Osteoarthritis Knee Score). Ann Rheum Dis 2008:67:206-11.

16 Kijowski R, Blankenbaker DG, Davis KW, et al. Comparison of 1.5- and 3.0-T MR Imaging for Evaluating the Articular Cartilage of the Knee Joint. Radiology 2009;250:839-48

17 Pelletier JP, Raynauld JP, Berthiaume MJ, et al. Risk factors associated with the loss of cartilage volume on weight-bearing areas in knee osteoarthritis patients assessed by quantitative magnetic resonance imaging: a longitudinal study. Arthritis Res Ther 2007;9:R74.

18 Wirth W, Eckstein F. A technique for regional analysis of femorotibial cartilage thickness based on quantitative magnetic resonance imaging. IEEE Trans Med Imaging 2008;27:737-44.

19 Wirth W, Hellio Le Graverand MP, et al. Regional analysis of femorotibial cartilage loss in a subsample from the Osteoarthritis Initiative progression subcohort. Osteoarthritis Cartilage 2009:17:291-7.

20 Hellio Le Graverand MP, Buck RJ, et al. Change in regional cartilage morphology and joint space width in osteoarthritis participants versus healthy controls - a multicenter study using 3.0 Tesla MRI and Lyon Schuss radiography. Ann Rheum Dis 2010;69:155-62.

21 Kellgren JH, Lawrence JS. Radiological assessment of osteo-arthrosis. Ann Rheum Dis 1957; 16:494-502.

22 Le Graverand MP, Vignon EP, Brandt KD, et al. Head-to-head comparison of the Lyon Schuss and fixed flexion radiographic techniques. Long-term reproducibility in normal knees and sensitivity to change in osteoarthritic knees. Ann Rheum Dis 2008;67:1562-6.

23 Kraus VB, Vail TP, Worrell T, et al. A comparative assessment of alignment angle of the knee by radiographic and physical examination methods. Arthritis Rheum 2005:52:1730-5

24 Eckstein F, Charles HC, Buck RJ, et al. Accuracy and precision of quantitative assessment of cartilage morphology by magnetic resonance imaging at 3.0 T. Arthritis Rheum 2005;52:3132-6.

25 Eckstein F, Hudelmaier M, Wirth W, et al. Double echo steady state magnetic resonance imaging of knee articular cartilage at 3 Tesla: a pilot study for the Osteoarthritis Initiative. Ann Rheum Dis 2006;65:433-41.

26 Krishnan N, Shetty SK, Williams A, et al. Delayed gadolinium-enhanced magnetic resonance imaging of the meniscus: an index of meniscal tissue degeneration? Arthritis Rheum 2007:56:1507-11.

27 Williams A, Sharma L, McKenzie CA, et al. Delayed gadolinium-enhanced magnetic resonance imaging of cartilage in knee osteoarthritis: findings at different radiographic stages of disease and relationship to malalignment. Arthritis Rheum 2005:52:3528-35. 


\section{Clinical and epidemiological research}

28 Joseph GB, Baum T, Alizai H, et al. Baseline mean and heterogeneity of MR cartilage T2 are associated with morphologic degeneration of cartilage, meniscus and bone marrow over 3 years-data from the Osteoarthritis Initiative. Osteoarthritis Cartilage 2012;20:727-35.

29 Outerbridge RE. The etiology of chondromalacia patellae. J Bone Joint Surg Br 1961;43-B:752-7.

30 Outerbridge RE, Dunlop JA. The problem of chondromalacia patellae. Clin Orthop Relat Res 1975;110:177-96.

31 Buck RJ, Wyman BT, Le Graverand MP, et al. Osteoarthritis may not be a one-way-road of cartilage loss-comparison of spatial patterns of cartilage change between osteoarthritic and healthy knees. Osteoarthritis Cartilage 2010;18:329-35.

32 Hellio Le Graverand MP, Buck RJ, et al. Subregional femorotibial cartilage morphology in women-comparison between healthy controls and participants with different grades of radiographic knee osteoarthritis. Osteoarthritis Cartilage 2009;17:1177-85.

33 Frobell RB, Nevitt MC, Hudelmaier M, et al. Femorotibial subchondral bone area and regional cartilage thickness: a cross-sectional description in healthy reference cases and various radiographic stages of osteoarthritis in 1,003 knees from the Osteoarthritis Initiative. Arthritis Care Res (Hoboken) 2010;62:1612-23.

34 Chen $\mathrm{MH}$, Wang JL, Wong $\mathrm{CY}$, et al. Relationship of chondrocyte apoptosis to matrix degradation and swelling potential of osteoarthritic cartilage. J Formos Med Assoc 2005;104:264-72.

35 Guermazi A, Niu J, Hayashi D, et al. Prevalence of abnormalities in knees detected by MRI in adults without knee osteoarthritis: population based observational study (Framingham Osteoarthritis Study). BMJ 2012;345:e5339.

36 Javaid MK, Lynch JA, Tolstykh I, et al. Pre-radiographic MRI findings are associated with onset of knee symptoms: the most study. Osteoarthritis Cartilage 2010;18:323-8. 


\section{ARD Association of changes in delayed} gadolinium-enhanced MRI of cartilage (dGEMRIC) with changes in cartilage thickness in the medial tibiofemoral compartment of the knee: a 2 year follow-up study using 3.0 T MRI

Michel D Crema, David J Hunter, Deborah Burstein, Frank W Roemer, Ling Li, Felix Eckstein, Nitya Krishnan, Marie-Pierre Hellio Le-Graverand and Ali Guermazi

Ann Rheum Dis 2014 73: 1935-1941 originally published online July 19, 2013

doi: 10.1136/annrheumdis-2012-203083

Updated information and services can be found at:

http://ard.bmj.com/content/73/11/1935

\section{These include:}

References This article cites 36 articles, 8 of which you can access for free at: http://ard.bmj.com/content/73/11/1935\#BIBL

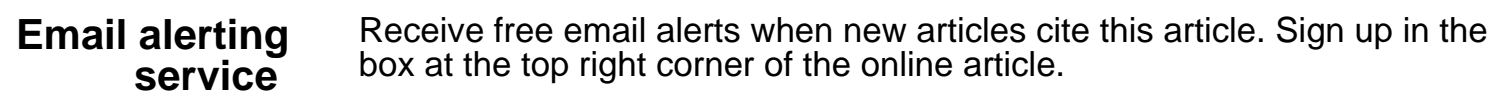

Collections

Articles on similar topics can be found in the following collections

Epidemiology (1360)

\section{Notes}

To request permissions go to:

http://group.bmj.com/group/rights-licensing/permissions

To order reprints go to:

http://journals.bmj.com/cgi/reprintform

To subscribe to BMJ go to:

http://group.bmj.com/subscribe/ 